\title{
Community Acquired Methicillin Resistant Staphylococcus Aureus (CA-MRSA) Infection in Paediatric Subcutaneous Abscesses in Pakistan
}

${ }^{1}$ Muhammad Ali Sheikh, ${ }^{1}$ Amna Idrees, ${ }^{1}$ Jamil Akhter Munir Ahmad, ${ }^{1}$ Kaneez Fatima, ${ }^{2}$ Lubna Riaz, ${ }^{1}$ Amna Ikram

${ }^{1}$ Department of Pediatric Surgery, Shaikh Zayed Medical Complex, Lahore

${ }^{2}$ Department of Pediatric Medicine, Shaikh Zayed Medical Complex, Lahore

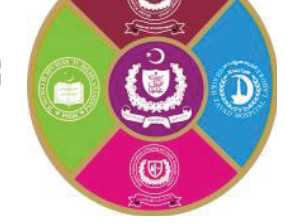

\begin{abstract}
Introduction: Staphylococcus aureus is one of the common pathogens of the human body. Previously a change in its sensitivity pattern was observed in which it became methicillin resistant but this strain was usually seen in hospital settings or in immunocompromised patients. Recently a changing trend has been observed in which a new variant of methicillin resistant staphylococcus aureus (MRSA) is being isolated specially in pediatric patients, who do not have any risk factors. This strain is labeled as community acquired MRSA.

Aims \& Objectives: To find the frequency of Community Acquired Methicillin-resistant Staphylococcus Aureus (CAMRSA) in paediatric sub-cutaneous abscesses.

Place and duration of study: A cross-sectional prospective study was conducted in Department of Paediatric Surgery Shaikh Zayed Medical Complex, Lahore from January 2017 till December 2020.

Material \& Methods: All the patients from 7 days to 14 years of age from both genders having subcutaneous abscesses were included. Neonates having hospital stay of more than 24 hours at birth were excluded. Patients having abscess secondary to any surgical intervention, recent hospitalization or trauma were also excluded. Patients were divided into four groups based on age. Pus samples were taken for culture \& sensitivity. Data analysis was performed using SPSS version 20 .

Results: There were 143 patients and 75 (52.4\%) of them were males. Patient were divided in groups on the basis of age. The most common location of abscess was head \& neck (43.4\%) followed by lower limbs and buttocks (30.1\%). The most common organism to grow was Staph. aureus (75\%) and out of these 107 cases $70(65.4 \%)$ had MRSA. No growth was obtained in $30(21 \%)$ patients. Other less common organisms were seen in $6(4 \%)$ cases. In less than 1 month of age of patients $76 \%$ had MRSA which was significantly higher than in other age groups (pvalue 0.047 ).

Conclusion: The frequency of CA-MRSA in paediatric subcutaneous abscesses is on the rise across the globe and more cases of invasive infections are being reported. So, population-based studies are required to assess the prevalence of this bacteria amongst paediatric population of Pakistan.
\end{abstract}

Key words: Community acquired Methicillin Resistant Staphylococcus Aureus, Pediatric, Subcutaneous abscess

\section{INTRODUCTION}

S Staphylococcus aureus (S. aureus) is one of the common pathogen of human body and the frequent cause of skin and soft tissue infections. Some of the strains of S. aureus are resistant to all beta lactam antibiotics and are labelled as methicillin resistant S. aureus. ${ }^{1}$ Methicillin-resistant Staphylococcus aureus (MRSA) was initially isolated in 1960s and since that time it has been spreading increasingly in the recent years ${ }^{2}$. Simultaneously the increase in community-acquired soft tissue abscesses in the pediatric population has been noted across the globe in last few years. Previously, MRSA infections were primarily hospital or institution acquired infections in patients with underlying risk factors. Several studies have shown that MRSA infections of otherwise healthy patients in the community are on the increase, with a reported incidence ranging from $33 \%$ to $69 \%$. $^{3}$ Soft tissue infections due to Community-acquired MRSA (CA-MRSA) are becoming increasingly prevalent in the pediatric population even in western population. ${ }^{4}$

Data from 43 children's hospitals represented in the Pediatric Health Information System was analyzed by, Gerber et al. and they reported an increase in MRSA soft tissue infections from $0.2 \%$ of admissions in 2002 to $1.1 \%$ of admissions in 2007 . Likewise, an analysis of discharge records in the United States National Center for Health Statistics demonstrated an increasing rate of community- 
acquired MRSA from 1996 to 2006, reaching an incidence of 25.5 cases per 100,000 children in $2006 .^{1,5}$

Doctors around the globe have been dealing with the complexity of management of MRSA for quite some time now. A few years back, the term MRSA was almost always associated with an infection that was hospital acquired. But since a decade or so the term community acquired MRSA (CA-MRSA) has emerged, which has brought along a whole new chapter of treatment and etiologies. ${ }^{6}$

The Centers for Disease Control and Prevention (CDC) Active Bacterial Core Surveillance Program defined a CA-MRSA case as a patient with an MRSA infection with no history of surgery, hospitalization, or residence in a medical facility within the year before infection, presence of a percutaneous device or indwelling catheter, dialysis within the previous year, hospitalization more than $48 \mathrm{~h}$ before MRSA culture, or previous MRSA infection or colonization. ${ }^{7}$

Although there have been research publications internationally on CA-MRSA, still there is insufficient data and information available on role of CA-MRSA in paediatric population of Pakistan, which led us to undertake the current research. Especially, there is lack of studies on CA-MRSA on local population except five cases reported by Agha Khan University Hospital Karachi. ${ }^{8}$

The aim of the study was to find the frequency of Community Acquired Methicillin-resistant Staphylococcus Aureus (CA-MRSA) in Paediatric sub-cutaneous abscesses.

\section{MATERIAL AND METHODS}

A cross-sectional prospective study was conducted in Department of Paediatric Surgery Shaikh Zayed Medical Complex, Lahore from January 2017 till December 2020.

All the patients from 7 days to 14 years of age from both genders having subcutaneous abscesses were included. Neonates having hospital stay of more than 24 hours at birth were excluded. Patients having abscess secondary to any surgical intervention, recent hospitalization for any other disease in last 2 years or trauma were also excluded. Patients were divided into four groups based on age. Pus samples of the all the patients were obtained for culture and sensitivity at the time of surgery. Most of the cases were managed on outpatient basis.

Patients were initially started on empirical antibiotics and later changed according to sensitivity report. Age of the patient, gender, area involved, temperature, hemoglobin levels, TLC count, weight of the patient and type of organism were recorded.

\section{Statistical analysis:}

Data was analyzed with SPSS version 20. Qualitative variables were analyzed with Chi square and $\mathrm{p}$ values were calculated.

\section{RESULTS}

During the study period 143 patients met the inclusion criteria. There were 75 (52.4\%) male patients and $57(40 \%)$ were less than 1 year of age. The age and gender distribution are shown in Table1. The most common location of abscess was head $\&$ neck (43\%), followed by lower limb \& buttocks $(30 \%)$. The details of location of abscess are shown in Table-2.

The most common bacteria to grow in pus was MRSA in $70(49 \%)$ patients, followed by Methicillin sensitive Staphylococcus aureus (MSSA) in 37 (26\%) patients and $30(21 \%)$ patients did not grow any bacteria. Other less common organisms were seen in $6(4 \%)$ cases. In less than 1 month of age patients $76 \%$ had MRSA which was significantly $(p=0.047)$ higher than in other age groups. The details are shown in Table-3. As the age of the patients increased the number of cases infected with MSSA increased. The most common location of abscesses was head \& neck and in these cases $50 \%$ had MRSA but the difference was not statistically significant. Comparison was also made between type of growth and TLC but no significant difference was observed, except that $50 \%$ of cases of MRSA had less than 11,000 TLC.

Growth of MRSA was common in female patients i.e., 41(58.6\%) out of total 70 cases of MRSA and it was statistically significant with $\mathrm{p}$ value of $=$ 0.033 . MSSA was slightly more common in male patients 29 out of $37(56.75 \%)$.

Fever was present in 71 patients, $33(46.5 \%)$ with MRSA and 23 (32.4\%) with MSSA had fever. Remaining 72 patients remained a febrile. (P value $=0.140)$.

Only $5(3.5 \%)$ of the patients had 2 or more abscesses, the remaining patients had a single abscess.

There was no significance of hemoglobin levels as compared to the type of growth. Hemoglobin levels of $30(50 \%)$ patients with MRSA were between 10.4-12.5 $(\mathrm{P}$ value $=0.942)$.

No significance of weight of the patient was found in relation to either location, age or type of growth. 


\begin{tabular}{|l|c|c|c|c|}
\hline Age Group & Male & Female & Total & Percentage \\
\hline$<1$ month & 12 & 17 & 29 & 20.3 \\
\hline $\begin{array}{l}\text { 2 month- } \\
\text { 12 months }\end{array}$ & 14 & 14 & 28 & 19.6 \\
\hline 1-5 years & 24 & 22 & 46 & 32.2 \\
\hline >5 years & 25 & 15 & 40 & 28.0 \\
\hline Total & $\mathbf{7 5}$ & $\mathbf{6 8}$ & $\mathbf{1 4 3}$ & \\
\hline
\end{tabular}

Table-1: Age \& gender distribution of patients $(n=143)$

\begin{tabular}{|l|c|c|}
\hline Area involved & No of cases & Percentage \\
\hline Head \& Neck & 62 & $43.4 \%$ \\
\hline Upper Limb & 18 & $12.6 \%$ \\
\hline Lower limb \& Buttocks & 43 & $30.1 \%$ \\
\hline Chest Wall & 9 & $6.3 \%$ \\
\hline Abdominal wall & 5 & $3.5 \%$ \\
\hline Back & 6 & $4.2 \%$ \\
\hline
\end{tabular}

Table-2: Distribution according to location of abscess

\begin{tabular}{|c|c|c|c|c|c|c|c|c|c|}
\hline & \multicolumn{2}{|c|}{ MSSA } & \multicolumn{2}{|c|}{ MRSA } & \multicolumn{2}{|c|}{$\begin{array}{c}\text { No } \\
\text { Growth }\end{array}$} & \multicolumn{2}{|c|}{ Others } & \multirow[t]{2}{*}{\begin{tabular}{|c|}
$P$ \\
value \\
\end{tabular}} \\
\hline & $\mathrm{n}$ & $\%$ & $\mathrm{n}$ & $\%$ & $\mathrm{n}$ & $\%$ & $\mathrm{n}$ & $\%$ & \\
\hline \multicolumn{10}{|l|}{ Age Groups } \\
\hline $\begin{array}{l}<1 \text { month } \\
(\mathrm{n}=29)\end{array}$ & 3 & 10.3 & 22 & 75.9 & 4 & 13.8 & 0 & 0.0 & \multirow{4}{*}{0.047} \\
\hline$<1$ year $(\mathrm{n}=28)$ & 9 & 32.1 & 15 & 53.6 & 3 & 10.7 & 1 & 3.6 & \\
\hline $\begin{array}{l}1-5 \text { years } \\
(n=46)\end{array}$ & 13 & 28.3 & 17 & 37.0 & 13 & 28.3 & 3 & 6.5 & \\
\hline $\begin{array}{l}>5 \text { years } \\
(\mathrm{n}=40)\end{array}$ & 12 & 30.0 & 16 & 40.0 & 10 & 25.0 & 2 & 5.0 & \\
\hline \multicolumn{10}{|l|}{ Gender } \\
\hline Male $(n=75)$ & 21 & 28.0 & 29 & 38.7 & 20 & 26.7 & 5 & 6.7 & \multirow{2}{*}{0.033} \\
\hline Female $(n=68)$ & 16 & 23.5 & 41 & 60.3 & 10 & 14.7 & 1 & 1.5 & \\
\hline \multicolumn{10}{|c|}{ Location of abscess } \\
\hline $\begin{array}{l}\text { Head\& Neck } \\
(\mathrm{n}=62)\end{array}$ & 14 & 22.6 & 31 & 50.0 & 15 & 24.2 & 2 & 3.2 & \multirow{6}{*}{0.350} \\
\hline $\begin{array}{l}\text { Upper Limb } \\
(\mathrm{n}=18)\end{array}$ & 2 & 11.1 & 10 & 55.6 & 6 & 33.3 & 0 & 0.0 & \\
\hline \begin{tabular}{|l|} 
Lower $\operatorname{limb} \&$ \\
Buttocks $(n=43)$
\end{tabular} & 15 & 34.9 & 18 & 41.9 & 6 & 14.0 & 4 & 9.3 & \\
\hline $\begin{array}{l}\text { Chest Wall } \\
(\mathrm{n}=9)\end{array}$ & 3 & 33.3 & 5 & 55.6 & 1 & 11.1 & 0 & 0.0 & \\
\hline $\begin{array}{l}\text { Abdominal } \\
\text { wall }(n=5)\end{array}$ & 1 & 20.0 & 2 & 40.0 & 2 & 40.0 & 0 & 0.0 & \\
\hline $\operatorname{Back}(n=6)$ & 2 & 33.3 & 4 & 66.7 & 0 & 0.0 & 0 & 0.0 & \\
\hline \multicolumn{10}{|c|}{ Total Leukocyte Count $\times 1000$} \\
\hline$<=11.0(\mathrm{n}=44)$ & 10 & 22.7 & 22 & 50.0 & 11 & 25.0 & 1 & 2.3 & \multirow{3}{*}{0.571} \\
\hline $\begin{array}{l}11.1-15.0 \\
(\mathrm{n}=45)\end{array}$ & 16 & 35.6 & 19 & 42.2 & 8 & 17.8 & 2 & 4.4 & \\
\hline$>15.1(\mathrm{n}=53)$ & 10 & 18.9 & 29 & 54.7 & 11 & 20.8 & 3 & 5.7 & \\
\hline
\end{tabular}

Table-3: Comparison of patient parameters with type of growth

\section{DISCUSSION}

Methicillin resistant Staph aureus (MRSA) was initially identified among hospitalized patients and remained predominantly a nosocomial infection till late 1980s. ${ }^{1}$ A new strain of MRSA started to appear in 1990s, which started to cause infections in healthy people and was labeled as community acquired MRSA (CA-MRSA). ${ }^{1,2}$

CA-MRSA is becoming a world-wide threat with studies reporting the increasing prevalence of nasal carriers of CA-MRSA. The proportion of CA MRSA isolates among all MRSA clinical isolates increased from $19.7 \%$ in 2007 to $36.4 \%$ in 2011 in Canada. ${ }^{4}$ In Spain, CA-MRSA rates increased over time while comparing 2004-2007 period (0.43\%) with 2008-2012 period (5.44\%). ${ }^{4}$ In Brazil, a study has reported CA-MRSA nasal colonization of $0.9 \%$ among healthy people living in the community, whereas $8.7 \%$ was found among adults with chronic wounds. ${ }^{4}$

CA- MRSA does not follow the usual risk factors that were previously associated with MRSA infection, like repeated antibiotic therapy, prolonged hospitalization, exposure to people already infected with MRSA. ${ }^{9}$ Risk factors for CA-MRSA infections have been identified in some studies, such as age, family history of staphylococcal infections, high body weight, previous use of antibiotics, aboriginal ethnicity, stay in day care settings and presentation during the spring. ${ }^{4}$ But we did not encounter similar risks in our study.

The most common organism cultured from subcutaneous abscesses in our study was Staphylococcus aureus which was noted in 107 cases $(75 \%)$. Out of these 107 cases $70(65.4 \%)$ had MRSA. This was comparable with other international studies; Olesevich et al. reported $66.3 \%$ and Rossini et al reported $74.75 \%$ infection with Staphylococcus Aureus in their patients. In these patients CA-MRSA was detected in majority of cases $49.2 \%$ by Olesevich and $66 \%$ by Rossini et al. ${ }^{2,7}$ This shows the trend that CA-MRSA is increasing in the general population. In current study CA-MRSA was significantly $(p=0.033)$ more common in females $(58.6 \%)$, similar finding was noted by Olesevich et $\mathrm{al}^{7}$ but the difference was not statistically significant in their study. A recent study from China observed similar results as our study with CA-MRSA being slightly more common $(52 \%)$ in females. ${ }^{10}$ No clear reason for this female preponderance in our patients could be found.

The patients were divided into groups based on their age and CA-MRSA was significantly $(\mathrm{p}=0.047)$ more common in less than 1 month of age patients. 
Similar findings were reported by Salazar et al. ${ }^{3}$ This could be due to the immature immune system in this age group which allows easy colonization by the organism and rapid spread of infection.

In our study $40 \%$ of patients were less than 1 year of age which was comparable with the study by Salazar $(41.2 \%)^{3}$ and Wang et al $(42 \%){ }^{10}$ This finding shows that CA-MRSA causes more invasive infections in younger age groups and is amongst the leading cause of skin and subcutaneous tissue infections in this population.

The most common location of abscess in our study was head \& neck which was seen in $43.4 \%$ of patients. The large number of cases in this area were on the occipital region. As per practice of our population the baby's head is rested against a firm surface to shape it. It results in pressure sore and infection on dependent occipital area. Rossini et al. reported buttocks to be the most common location $(41.5 \%)$ in their study. The second most common location in our study was buttocks and lower limbs $(30.1 \%)$. Buttocks are more vulnerable because of commonly occurring diaper rash resulting in breach of skin barrier and bacteria could easily enter in the subcutaneous tissue and cause infection.

We correlated presence of fever, hemoglobin levels, and weight of the children with type of growth and did not find any significant relation. In patients with CA-MRSA total leukocyte count was less than 11,000 in $50 \%$ of cases which show poor response from immune system against the bacteria, specially in less than 1 year age group.

There are some studies from Asian countries which have highlighted the menace of rising trend of CAMRSA in this part of the world as well. Immergluck et al. conducted an epidemiological study and found that CA-MRSA rates increased at higher rates compared to non-resistant forms (MSSA), $\mathrm{p}=0.01$. Children with no public health insurance had higher odds of CA-MRSA infection. Black children were almost 1.5 times as likely as white children to have CA-MRSA infections (OR 95\% CI 1.44,1.75, p < 0.0001). ${ }^{11}$ Alaklobi et al. studied children between 1 month to 13 years for nasal carriage of CA-MRSA and found that $20 \%$ of their patients were carrying Staph aureus and 23\% among them were having MRSA. ${ }^{12}$ A study by Rodriguez et al. reported that the prevalence of CA-MRSA increased from $21 \%$ between $2009-2010$ to $54 \%$ between $2012-2013$ and most of them $(74 \%)$ caused skin \& soft tissue infections in children. ${ }^{13}$

Alzomar et al. reported bones and joint infections, deep seated abscesses, necrotizing pneumonia and infective endocarditis that were caused by CAMRSA in children. ${ }^{14}$ They concluded that CA-
MRSA infections could become invasive and infect previously healthy children with no known risk factors making it one of the virulent organisms. Invasive diseases may comprise of bacteremia related with metastatic areas of infection like endocarditis, bone \& joint infections and necrotizing pneumonia. Incidence of CA-MRSA seems to be variable, but with these types of invasive infections, the knowledge of the wide range of CA-MRSA disease among the treating physicians is important because of early identification and start of effective empirical antibiotics is important.

The current study confirms that CA-MRSA is an emerging pathogen not only in paediatric population of Pakistan but also in other parts of the world, accounting for approximately one third of all S.aureus strains isolated from children with severe community-acquired infections. Moreover, we noticed a trend of increasing incidence density over the four-year period of the study. A large population-based study should be conducted to know the carrier state of MRSA.

\section{CONCLUSION}

The frequency of CA-MRSA in paediatric subcutaneous abscesses is on the rise across the globe and more cases of invasive infections are being reported. The choice of empirical antibiotics should be based on common organisms found in a particular population. So, population-based studies are required to assess the prevalence of this bacteria amongst paediatric population of Pakistan.

\section{REFERENCES}

1. Dukic V, Lauderdale D, Wilder J, Daum R, David M. Epidemics of community-associated methicillinresistant Staphylococcus aureusin the United States: a meta-analysis. PLoS ONE. 2013; 8 (1) e52722.

2. Rossini C, Moriarty K, Tashjian D, Garb J, Wait R. Geographic distribution of community-acquired methicillin-resistant Staphylococcus aureus soft tissue infections. J Pediatr Surg 2011; 46: 1089-92.

3. Salazar-Ospina L, Jiménez JN. High frequency of methicillin-susceptible and methicillin-resistant Staphylococcus aureus in children under 1 year old with skin and soft tissue infections. J Pediatr (Rio J). 2018; 94(4):380-389.

4. Paternina-dela-Ossa R, Prado SI, Cervi MC, Lima DAFS, Martinez R, Bellissimo-Rodrigues F. Is community associated methicillin resistant Staphylococcus aureus an emerging pathogen among children in Brazil? Braz Jour Infec Dis. 2018; 22(5):371-376.

5. Gerber JS, Coffin SE, Smathers SA, et al. Trends in the incidence of methicillin-resistant Staphylococcus 
aureus infection in children's hospitals in the United States. Clin Infect Dis 2009; 49:65-7.

6. Frei CR, Miller ML, Lewis JS, Lawson KA, Hunter JM, Oramsionwu CU et al. Trimethoprim Sulfamethoxazole or Clindamycin for CommunityAssociated MRSA (CA-MRSA) Skin Infections. J Am Board Fam Med. 2010; 23:714-19.

7. Olesevich M, Kennedy A. Emergence of community acquired methicillin resistant Staphylococcus aureus soft tissue infections. J Pediatr Surg 2007; 42:765768 .

8. Khalid M, Junejo S, Mir F. Invasive community acquired methicillin resistant staphylococcal aureus infections in children. J Coll Physicians Surg Pak 2018; 28 (Special supplement):174-77.

9. Frei CR, Makos BR, Daniels KR, Oramsionwu CU. Emergence of community-acquired methicillinresistant Staphylococcus aureus skin and soft tissue infections as a common cause of hospitalization in United States children. J Pediatr Surg 2010; 45: 1967-1974.

10. Wang X, Shen Y, Huang W, Zhou Y. Characterization of community acquired Staphylococcus aureus causing skin and soft tissue infections in a children's hospital in Shanghai, China. Epidemiology and Infection 147, 2019, e323, $1-6$.

11. Immergluck LC, Leong T, Malhotra K, Parker TC, Ali F, Jerris RC et al. Geographic surveillance of community associated MRSA infections in children using electronic health record data. BMC Infect Dis 2019; 19:170

12. Alaklobi F, Aljobair F, Alrashod A, Alhabibi R, Alshamrani M, Alamin W et al. The prevalence of community associated methicillin resistant Staphylococcus aureus among outpatient children in a tertiary hospital: A prospective observational study in Riyadh, Saudi Arabia. Int J Pediatr Adolesc Med 2015; 2:136-140.

13. Rodríguez F, Salinas C, Fernandez S, Haim S, Mollerach M, Basualdo W et al. Communityassociated methicillin-resistant Staphylococcus aureus (CA-MRSA) clones from Paraguayan children. J Infect Dev Ctries 2020; 14(3):290-297.

14. Alzomar O, Alfawaz $T$, Alshahrani D. Invasive community acquired methicillin resistant
Staphylococcus aureus (CA-MRSA) infection in children: case series and literature review. Int $\mathrm{J}$ Pediatr Adolesc Med. 2017; 4:119-123.

\section{The Authors:}

Prof. Muhammad Ali Sheikh

Head, Department of Pediatric Surgery, Shaikh Zayed Medical Complex, Lahore.

Dr. Amna Idrees

P.G. Trainee,

Department of Pediatric Surgery,

Shaikh Zayed Medical Complex, Lahore.

Dr. Jamil Akhter Munir Ahmad

Senior Registrar,

Department of Pediatric Surgery,

Shaikh Zayed Medical Complex, Lahore.

Dr. Kaneez Fatima

Medical Officer,

Department of Pediatric Surgery,

Shaikh Zayed Medical Complex, Lahore.

Dr. Lubna Riaz

Assistant Professor,

Department of Pediatric Medicine,

Shaikh Zayed Medical Complex, Lahore.

Dr. Amna Ikram

P.G. Trainee,

Department of Pediatric Surgery,

Shaikh Zayed Medical Complex, Lahore.

\section{Corresponding Author:}

Prof. Muhammad Ali Sheikh

Head, Department of Pediatric Surgery, Shaikh Zayed Medical Complex, Lahore. E-mail: drali444@yahoo.com 